\title{
DETERMINATION OF THE PROPERTIES OF BAMBUSA BLUMEANA USING FULL-CULM COMPRESSION TESTS AND LAYERED TENSILE TESTS FOR FINITE ELEMENT MODEL SIMULATION USING ORTHOTROPIC MATERIAL MODELING
}

\author{
Ma. Doreen Esplana Candelaria ${ }^{1}$ and Jaime Yabut Hernandez, Jr. ${ }^{2}$ \\ ${ }^{1}$ Assistant Professor, Institute of Civil Engineering, University of the Philippines Diliman, Quezon City, \\ Philippines, Tel: +639173092893,+821041512893, e-mail: mecandelaria@ up.edu.ph \\ ${ }^{2}$ Associate Professor, Institute of Civil Engineering, University of the Philippines Diliman, Quezon City, \\ Philippines, e-mail: jhernandezmail@gmail.com
}

Received Date: October 12, 2018; Revised Date: May 13, 2019; Acceptance Date: May 16, 2019

\begin{abstract}
Construction materials are selected based on two factors: structural integrity and economy. However, there is an emerging issue with regards to building materials, and that is sustainability, which considers the environmental load of a construction material. Bamboo's lightweight and flexibility make it a good alternative for residential construction in seismic. In this study, bamboo was tested for its material properties. Layered tensile tests and full-culm compressive tests were done to get the material properties of the bamboo. The top part of the bamboo culm recorded the highest tensile strength per layer, with its outer layers having tensile strength as high as $600 \mathrm{MPa}$. The tensile strength of its middle and inner layers, on the other hand, were approximately 450 $\mathrm{MPa}$ and $180 \mathrm{MPa}$, respectively. As for the compressive strength, the top part of the bamboo culm recorded the highest compressive strength with an average of $76.84 \mathrm{MPa}$. The middle part of the bamboo culm recorded the lowest compressive strength with an average of $62.55 \mathrm{MPa}$. The bottom part of the bamboo culm recorded an average compressive strength of $69.49 \mathrm{MPa}$. These properties were then used to construct an orthotropic material model and simulate the stresses using finite element modeling. The FEM model of a simply-supported beam with a concentrated load at midspan was made. To validate the orthotropic material model for bamboo, three-point bending tests of bamboo beams were conducted and compared with the simulation results. The results show that in modeling the material properties of the bamboo to check for deflections, the orthotropic model gives more accurate results.
\end{abstract}

Keywords: Bamboo, Compressive strength, Construction material, Finite modelling analysis, Tensile strength

\section{Introduction}

\section{Background of the Study}

Existing infrastructure in the Philippines is always heavily damaged by hazards caused by typhoons and at times, by large-magnitude earthquake. Most of the time, most damages happen in the provinces or in the rural areas. It is important to build a resilient community by providing sustainable community housing that uses sustainable materials. For a community to be resilient, it should have a sustained ability to utilize available resources to withstand adverse situations. One of the common materials used in construction of simple houses in the country is bamboo because of its abundance. 
Typhoon calamities happen all year round so it is crucial to provide a better design on the said sustainable community housing systems, considering both structural and economical aspects of such system. Because of the country's economic standing and said situations, the need to look for affordable and sustainable construction materials is also increasing.

Construction or building materials are generally selected based on two factors: structural integrity and economic feasibility. However, there is an emerging issue with regards to building materials, and that is sustainability. Due to environmental conservation and preservation issues, it became important to consider the environmental load of a certain construction material. A critical aspect of sustainable infrastructure is its ability to perform under both service conditions and extreme events. It is now within the international context that we start considering natural fibers, specifically bamboo, as a viable, sustainable, and engineered alternative construction material in many areas of the world. [1] Approximately, there are a total of more than 1000 species of bamboo in the world. The common types of bamboo used in construction are those that are under the woody "group." [2] Bamboo's lightweight and flexibility make it a good appealing alternative for residential construction in seismic regions like the Philippines. In Indonesia, researchers are now utilizing bamboos as reinforcement in concrete structures due to the finding that the tensile strength of bamboo fiber is relatively greater than that of the ordinary structural steel [3]. Bamboo is a renewable and versatile material, which is characterized by its high strength and low weight. [4] Because of its abundance in the country, growing almost everywhere, it became a staple construction material especially to those living in the rural areas. However, the use of bamboo as a construction material is not universally accepted. This is because of some limitations in durability, jointing techniques, flammability, and the lack of design guidelines and standardization for this type of material. [4] In order to have proper design guidelines and standardization for bamboos, it is best to understand first its material properties. Bamboo is often paralleled to wood or timber because of their similarities in chemical structure. The material properties as well as the physical structure are the characteristic that differentiates bamboo from wood.

To aid in the increasing focus on the standardization process for such material, this study aims to determine the bamboo's material and mechanical properties. Test results on these properties are already available but they are mostly average values. This means that the tests that were done did not fully consider the layered structure of the bamboo fibers and the bind that holds these fibers.

After the tests are done, the second objective of this study is to construct a multilayered model of the bamboo material as an orthotropic material. The basis for this model will be the results of the test conducted earlier. Moreover, this study aims to develop a finite element model for a bamboo beam that will be validated using experimental results.

Though there have been studies reporting the high strength of bamboos, the level of confidence associated with the seismic analysis and design of bamboo-based constructions is lower than those of concrete or steel constructions. Therefore, this is also for the improvement on the understanding of the state-of-practice of analysis and design of bamboo-based structures. [4]

Because of the complications in the preparation of test specimens and the lack of test methods for layered material properties of bamboo, only the tensile test will be performed using bamboo layer specimens. Full culm compressive and bending tests would also be done considering the position of the sample along the length of the bamboo. The tests will be performed in a universal testing machine available in the laboratory of 
the Institute of Civil Engineering. The bamboo that will be used in the test is the Kauayan Tinik - bamboo species commonly used for structural purposes in the Philippines. These tests will provide both material properties for the bamboo fibers and the binders.

Simulation model of the bamboo would be constructed in ANSYS, finite element model software. The model would be in 3D with the load applied in the direction perpendicular to the material's cross-section. Model inputs such as the material properties, mechanical properties, bamboo dimensions, and support conditions would be based on the actual tests that will be conducted. [5]

Three strength tests would be done using a universal testing machine. Specimens would be obtained from the three main parts of a bamboo culm: top, middle, and bottom portions. From each of these portions, at least for the tensile strength test, three layers within the bamboo culm will be tested: outer, middle, and inner layers.

Finally, after conducting the said tests, a material model of the bamboo would be developed, and a simulation beam model will be constructed using ANSYS.

Microstructural analysis on the specimens before and after testing will help verify the outcomes of the experiments. With this, characterization on the bamboo's fibers and composition may be obtained which may further provide evaluation on the material's strength.

\section{Methodology}

\section{Experimental Phase}

The study conducted three strength test experiments on bamboo: tensile, compressive, and flexure tests. Bamboo samples were divided into layers: inner, middle, and outer layers for tensile tests. These samples were gathered along the length of the bamboo's culm. To facilitate easy sampling, the bamboo culm was also divided into three parts: bottom, middle, and top parts.

There were two INSTRON Universal Testing Machines used for this study. For tensile strength tests, 3366 INSTRON Universal Testing Machine was used. This machine has a maximum load capacity of up to $10 \mathrm{kN}$. The attachment used by the instrument to properly hold the specimens are flat and made of rough rubber in order to reduce possible slippage of the specimens that will be tested.

For compressive and flexural tests, 5982 INSTRON Universal Testing Machine was used. The maximum load capacity of this equipment is $100 \mathrm{kN}$. Fabricated attachment and/or supports were used for flexural tests. For compressive strength tests, the steel plate that is originally attached to the equipment was used.

\section{Tensile Strength Test}

There are available test methods from ISO $22517-1$ or Bamboo Determination of Physical and Mechanical Properties (ISO 2004b) for all the strength tests for bamboo culms. The tests for bamboo layers were conducted following ISO 2004b methods and the ASTM D143-09 Standard Test Methods for Small Clear Specimens of Timber. The two methods served as guides in designing the test methods for the bamboo layers.

The International Organization for Standardization (ISO) suggested the use of a "dogbone" specimen for the tensile tests parallel to grains at internodes. This "dogbone" specimen includes a reduced area gage length which helps enhance failure at the neck. 
This technique was done to minimize failure at the grip area. The test was done with a compressive loading rate of $0.6 \mathrm{~mm} / \mathrm{min}$.

\section{Compressive Strength Test}

The specimens were taken from the same culms that were used to test for tensile strength. The ASTM D143-09 Standard Test Methods for Small Clear Specimens of Timber was used as a guide in conducting the test as the available size of the bamboo samples were small.

The test was done with a compressive loading rate of $0.6 \mathrm{~mm} / \mathrm{min}$.

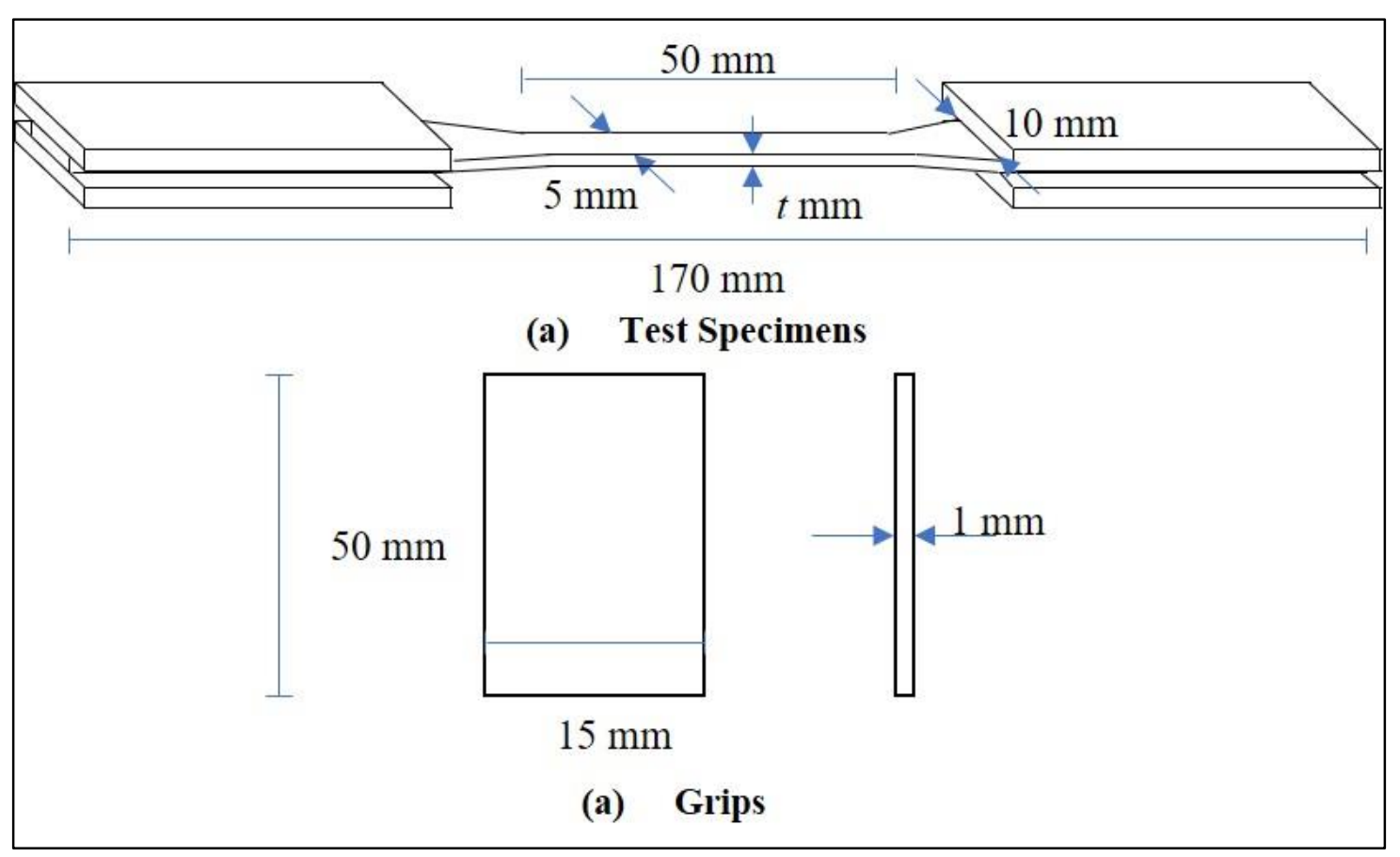

Figure 1. Dogbone style for layered tensile strength test

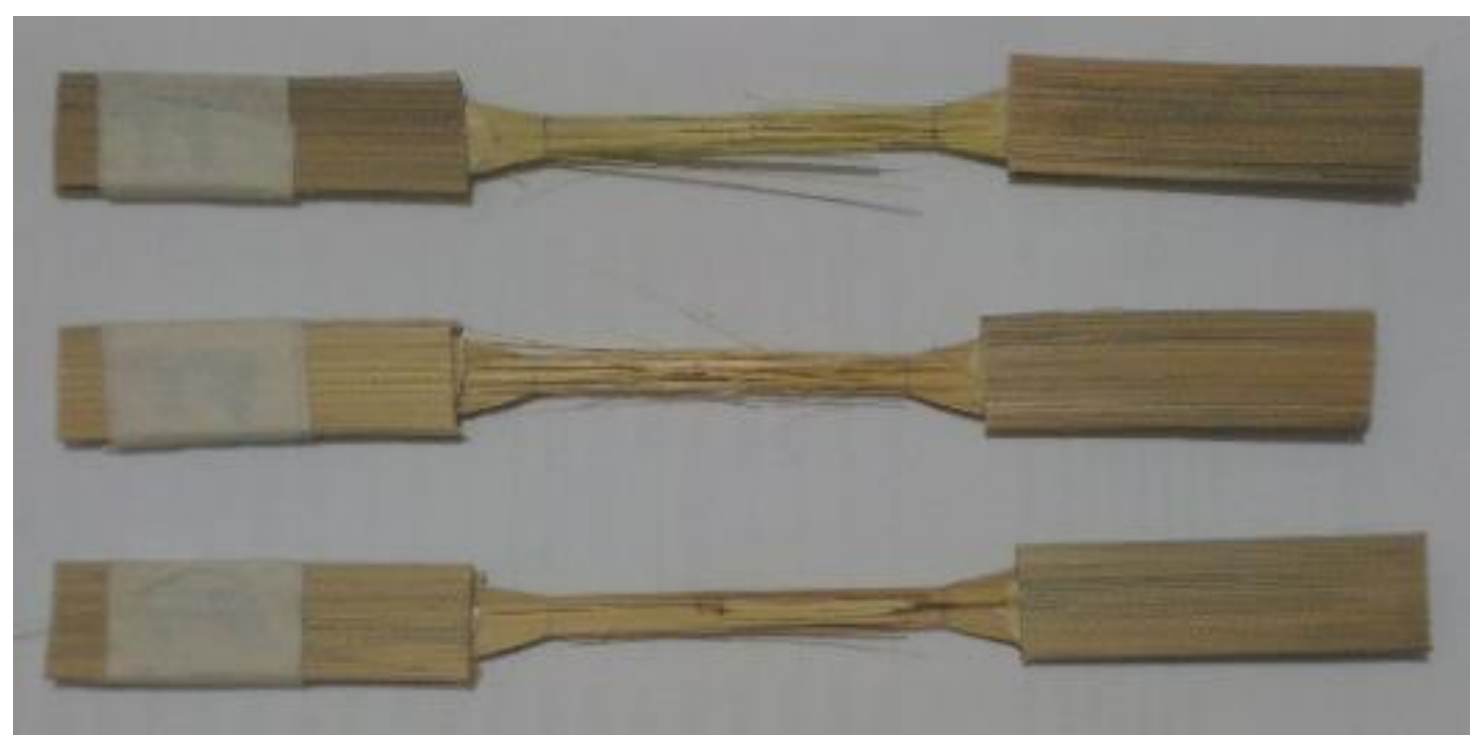

Figure 2. Tensile strength tested specimens 


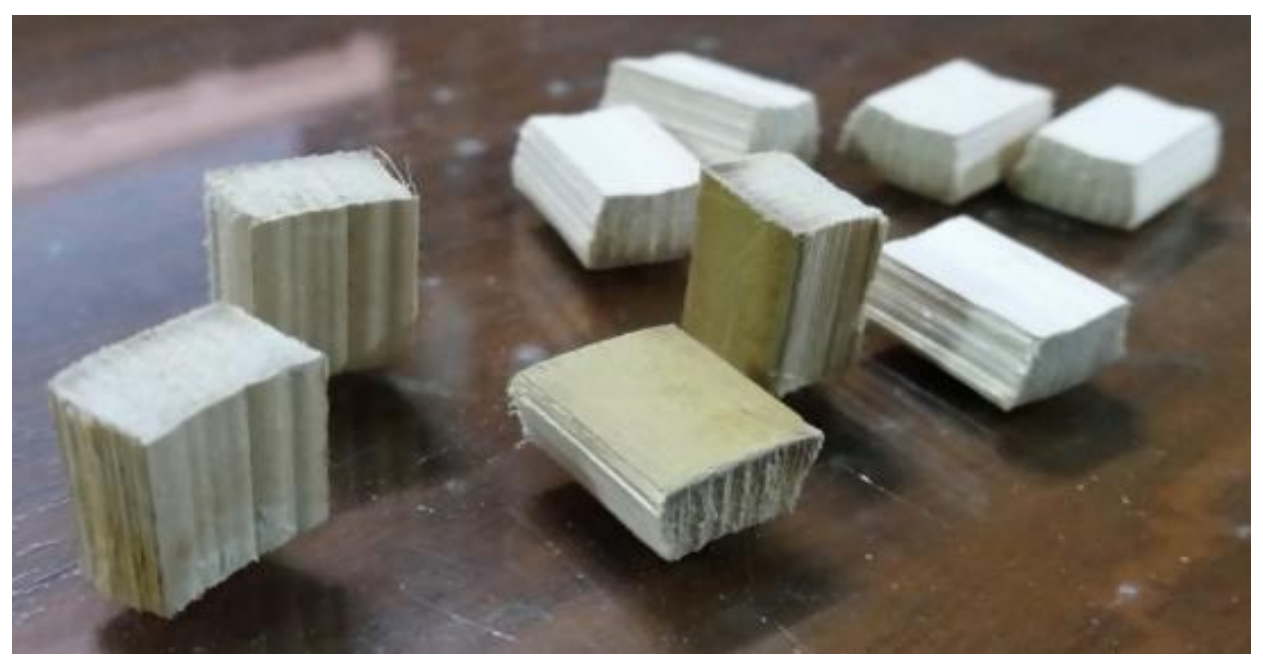

Figure 3. Compressive strength test specimens
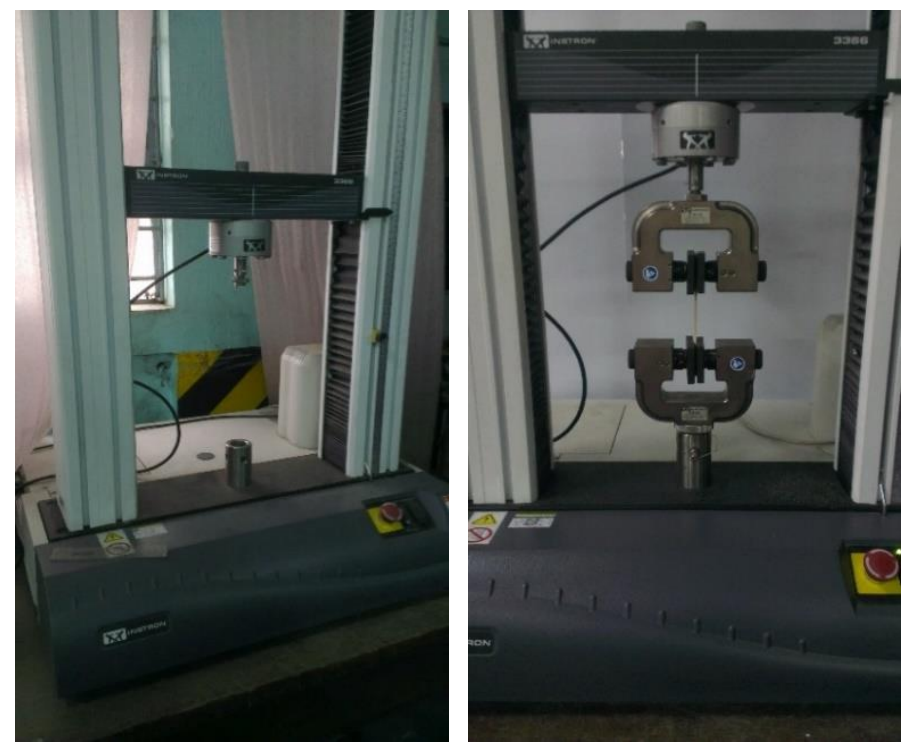

Figure 4. Tensile strength test set-up

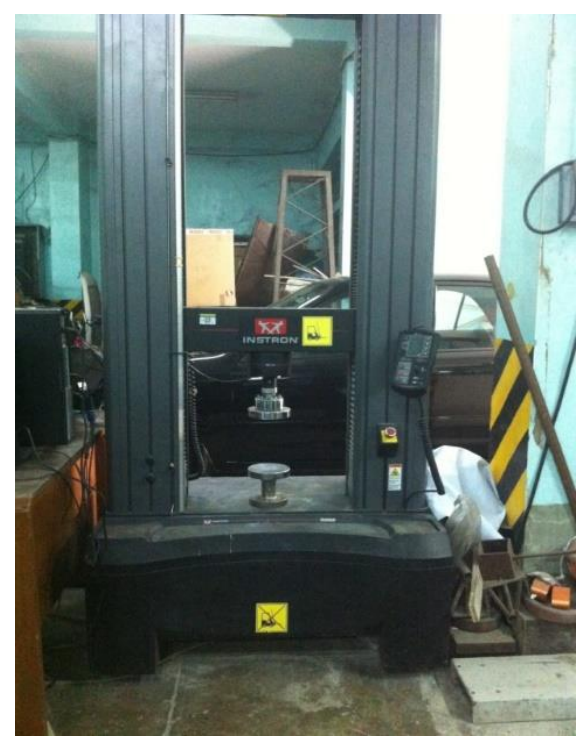

Figure 5. Compressive strength test set-up 


\section{Flexural Strength Test}

Similar to tensile and compressive strength tests, the specimens for the flexural strength tests were taken from the same culm. The ASTM D143-09 Standard Test Methods for Small Clear Specimens of Timber was used as a guide in doing the said test.

Small samples were cut from the bamboo culm using a speed cutter to ensure that the specimens were cut properly. First, thick long strips were cut from the culms. Since the bamboo culms are cylindrical in shape, it is necessary to have samples that are nearly rectangular in shape to ensure that the standard used for testing was followed. Samples were also taken from the top, middle, and bottom portions of the culm, similar to the samples for the tensile strength test. The size of the specimens depended on the thickness of the bamboo being tested. There are different specimen sizes for each portion of the bamboo culm. On average, the thickness of specimens is equal to $10.75 \mathrm{~mm}$.

There were approximately 12 specimens from the bamboo culm. The test was done with a compressive loading rate of $1 \mathrm{~mm} / \mathrm{min}$.

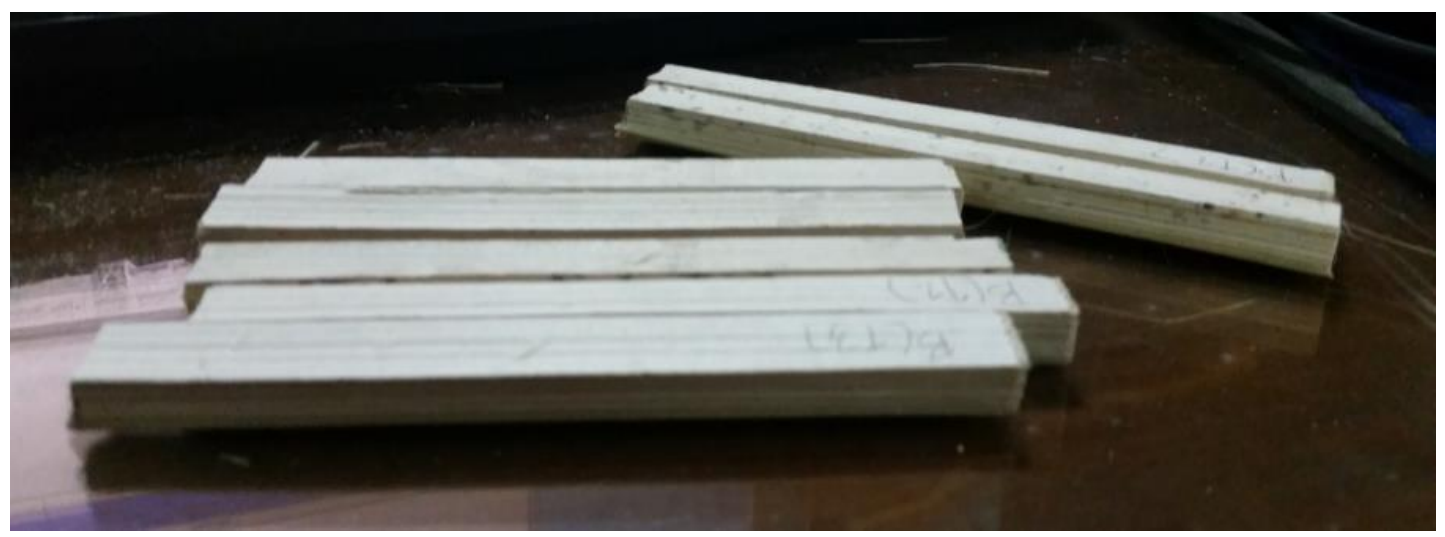

Figure 6. Flexural strength test specimens

\section{Modeling Phase}

The results from the experiment will be used to validate the deflection obtained from the simulation model done in ANSYS. For the material model, the bamboo culm was assumed to exhibit an orthotropic property.

In order to properly model the bamboo properties, the classification of materials should be discussed first. In general, there are three classifications of materials: isotropic, anisotropic, and orthotropic materials.

If the mechanical properties of a material are uniform in any directions, that material is called isotropic material. This type of materials is easier to analyze because their behavior when under an applied loading are easier to predict. On the contrary, anisotropic materials are materials whose physical properties are directionally dependent. Modulus of elasticity is an example of this type of material because it depends on the direction of the load being applied to the material. Orthotropic material, on the other hand, is a subset of anisotropic material. Orthotropic material is a material that has different material properties in different orthogonal directions.

Isotropy and anisotropy can also be distinguished based on their stiffness matrix, specifically, on their elastic constants. Isotropic materials have 2 independent elastic constants while anisotropic materials have 21 independent elastic properties. When the symmetric property of orthotropic material is applied, the number of independent elastic 
constants converts to 9. In this study, bamboo was considered as an orthotropic material because of the orientation of its fibers.

\section{Bamboo as a Composite Material}

The bamboo layers were modeled as laminated composite with several unidirectional continuum layers each with unique mechanical properties. The properties - Modulus of Elasticity and Poisson's ratio - obtained from the tensile and compressive tests were used to model the bamboo culm as a laminated composite. This is done to investigate the effects of the individual mechanical properties of each layer to the overall strength of the material.

Elastic constants, parallel to the grains, were obtained from the stress-strain graphs of the tensile strength and compressive strength tests. For the tensile strength test, the modulus of elasticity was obtained by getting the highest value of the stress and dividing it by the corresponding strain. For the compressive strength tests, the elastic constant was obtained from the linear part of the compressive stress-strain graph, following Hooke's law for isotropic materials. For each curve on the graph (in all bamboo parts: top, middle, bottom), points not on the linear part of the curve were not considered and the remaining linear part of the curve were analyzed for linear regression to get the slope of the line, which would eventually, help calculate the modulus of elasticity.

The elastic constants that were computed are summarized in Table 1. Other properties were calculated or obtained from literatures for the whole material such as Modulus of Elasticity perpendicular to the grain/ fiber orientation and the Modulus of Rigidity.

Table 1. Material Properties for the Orthotropic/Isotropic Model

\begin{tabular}{|c|c|c|c|}
\hline $\begin{array}{c}\text { TENSILE STRENGTH } \\
\text { TEST }\end{array}$ & INNER LAYER & MIDDLE LAYER & OUTER LAYER \\
\hline $\begin{array}{c}\text { YOUNG'S MODULUS } \\
\text { (PARALLEL) }\end{array}$ & $3572.89 \mathrm{MPa}$ & $9861.50 \mathrm{MPa}$ & $12283.43 \mathrm{MPa}$ \\
\hline $\begin{array}{c}\text { YOUNG'S MODULUS } \\
\text { (PERPENDICULAR) }\end{array}$ & $125.05 \mathrm{Mpa}$ & $345.15 \mathrm{MPa}$ & $429.92 \mathrm{MPa}$ \\
\hline $\begin{array}{c}\text { POISSON'S RATIO } \\
\text { (PARALLEL) }\end{array}$ & 0.28 & 0.28 & 0.28 \\
\hline $\begin{array}{c}\text { POISSON'S RATIO } \\
\text { (PRPENDICULAR) }\end{array}$ & 0.0098 & 0.0098 & 0.0098 \\
\hline $\begin{array}{c}\text { COMPRESSIVE } \\
\text { STRENGTH TEST }\end{array}$ & INNER LAYER & MIDDLE LAYER & OUTER LAYER \\
\hline $\begin{array}{c}\text { YOUNG'S MODULUS } \\
\text { (PARALLEL) }\end{array}$ & $1608.87 \mathrm{MPa}$ & $1608.87 \mathrm{MPa}$ & $1608.87 \mathrm{MPa}$ \\
\hline $\begin{array}{c}\text { YOUNG'S MODULUS } \\
\text { (PERPENDICULAR) }\end{array}$ & $58.48 \mathrm{MPa}$ & $58.48 \mathrm{MPa}$ & $58.48 \mathrm{MPa}$ \\
\hline $\begin{array}{c}\text { POISSON'S RATIO } \\
\text { (PARALLEL) }\end{array}$ & 0.12 & 0.12 & 0.12 \\
\hline $\begin{array}{c}\text { POISSON'S RATIO } \\
\text { (PRPENDICULAR) }\end{array}$ & 0.0098 & 0.0098 & 0.0098 \\
\hline
\end{tabular}

Tensile test perpendicular to the grain/fiber of the bamboo was not performed due to limited guidelines on doing the test. However, Torres et al. [6], Jiang et al. [7] and 
Yu et al. [8] suggested that there is a relationship between the longitudinal modulus of elasticity and the modulus of elasticity perpendicular to the grains. Equation 1 shows the relationship between longitudinal and modulus of elasticity of bamboo perpendicular to the grains [8]

$$
\frac{E_{\text {transv }}}{E_{\text {long }}}=0.035
$$

where $\mathrm{E}_{\text {trans }}=$ modulus of elasticity perpendicular to the grains

$\mathrm{E}_{\text {long }}=$ longitudinal modulus of elasticity.

\section{Modeling Bamboo in ANSYS}

A portion of the bamboo culm - shaped as a rectangular beam - was modeled in ANSYS $®$ (Academic Research Multiphysics, Release 16.1) using an orthotropic material model and an isotropic material model with layered sections. Each layer was assumed bonded completely with other layers.

The properties used for the orthotropic model were checked using Hooke's Law for orthotropic materials. The properties for each layer were entered in the compliance matrix. The strain corresponding to a particular loading in the experiment was also entered in the equation. The corresponding stress was computed to check if it would agree with the results from the tensile test conducted. Since the properties were obtained using the uniaxial tensile strength test, only the tensile strain was entered in the equation to get the corresponding uniaxial tensile stress. Equation 2 shows Hooke's Law for orthotropic materials.

After checking the properties for orthotropic model, the location of the neutral axis was determined to define the layers of the rectangular beam. This was done to assign the material properties correctly. After calculating for the correct location of the neutral axis, the rectangular beam was modeled with 4 layers. Three layers are under tensile behavior while the remaining layer is under compressive behavior. The model duplicated the three-point bending test done for the rectangular beam. The maximum load or the load at failure obtained for each specimen from the test was used for the modelling of the beam in ANSYS.

$$
\left[\begin{array}{c}
\varepsilon_{x x} \\
\varepsilon_{y y} \\
\varepsilon_{z z} \\
\varepsilon_{y z} \\
\varepsilon_{x z} \\
\varepsilon_{x x} \\
\varepsilon_{x y}
\end{array}\right]=\left[\begin{array}{cccccc}
\frac{1}{E_{x}} & \frac{-v_{y x}}{E_{y}} & \frac{-v_{z x}}{E_{z}} & 0 & 0 & 0 \\
\frac{-v_{x y}}{E_{y}} & \frac{1}{E_{y}} & \frac{-v_{z y}}{E_{z}} & 0 & 0 & 0 \\
\frac{-v_{x z}}{E_{z}} & \frac{-v_{y z}}{E_{z}} & \frac{1}{E_{z}} & 0 & 0 & 0 \\
0 & 0 & 0 & \frac{1}{2 G_{y z}} & 0 & 0 \\
0 & 0 & 0 & 0 & \frac{1}{2 G_{x z}} & 0 \\
0 & 0 & 0 & 0 & 0 & \frac{1}{2 G_{x y}}
\end{array}\right]\left[\begin{array}{c}
\sigma_{x x} \\
\sigma_{y y} \\
\sigma_{z z} \\
\sigma_{y z} \\
\sigma_{x z} \\
\sigma_{x x} \\
\sigma_{x y}
\end{array}\right]
$$

Deflection and the normal stress were then calculated for each maximum load recorded. The results of deflection and stresses from the ANSYS model were then compared to the results from the experiment and from the mechanical analysis, respectively. For the mechanical calculations, the concept of the transformed section in Mechanics was used to locate the neutral axis and to solve for the maximum compressive 
and tensile stresses. It was assumed that all layers are under isotropic behavior. The succeeding chapter will discuss the location of the neutral axis and the computation of the tensile and compressive stresses.

\section{Normal Stresses of Bamboo in Layers}

The location of neutral axis and the stresses were calculated using the concept of transformed section in Mechanics.

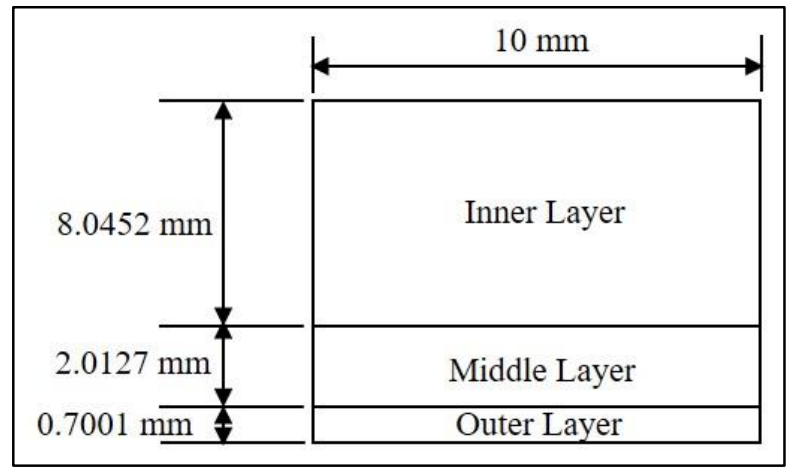

Figure 7. Layered configuration of the rectangular beam for the location of the neutral axis

Below are the computed material properties that would be used to locate the neutral axis and compute for the tensile and compressive stresses.

Material Properties:

$$
\begin{aligned}
& E_{\text {inner layer }}=3572.8933 \mathrm{MPa} \\
& E_{\text {middle layer }}=9861.4985 \mathrm{MPa} \\
& E_{\text {outer layer }}=12283.4344 \mathrm{MPa}
\end{aligned}
$$

The location of the neutral axis and consequently, the moment of inertia, were then computed. Then, the tensile and compressive stresses were calculated based on the values computed earlier. The flexure formula for transformed section is shown in Equation 3.

$$
\begin{aligned}
& \sigma_{\text {compression }}=\frac{M^{*} y_{C}}{I} \\
& \sigma_{\text {tension }}=\frac{M^{*} y_{T}}{I} * n_{2}
\end{aligned}
$$

where $\sigma_{\text {compression }}=$ compressive stress

$\sigma_{\text {tension }}=$ tensile stress

$\mathrm{M}=$ maximum bending moment

$\mathrm{y}_{\mathrm{C}}=$ distance of the outermost compressive fiber from the neutral axis

$\mathrm{y}_{\mathrm{T}}=$ distance of the outermost tensile fiber from the neutral axis

$\mathrm{I}=$ moment of inertia with respect to the neutral axis

$\mathrm{n}_{2}=$ transformation number (moduli ratio)

Finite Element Model Formulation for Bamboo Beam

A computer program, ANSYS, was used for the formulation of the finite element model of the orthotropic material bamboo beam model. The same program was also used for the 
simulation of this model under a flexure load and the calculation of the deflection and stresses of the bamboo beam.

\section{Results and Discussion}

\section{Tensile Strength Test}

From the experiments conducted, the outer layers of the top part recorded the highest tensile strength of approximately $600 \mathrm{MPa}$, whereas the inner layers recorded the lowest. It may be seen from the values gathered that the tensile strengths of the outer layers are almost twice that of the average tensile strength of the three layers.

Similar to the top part, the outer layers of the middle part of the bamboo recorded the highest tensile strength of approximately $500 \mathrm{MPa}$. The inner layers also have the weakest tensile strength of about $160 \mathrm{MPa}$.

The outer layers of the bottom part recorded the highest tensile strength as compared to that of its middle and inner layers. The tensile strength of the outer layers was observed to be approximately equal to $400 \mathrm{MPa}$, while its inner layers recorded the lowest, roughly around $60 \mathrm{MPa}$.

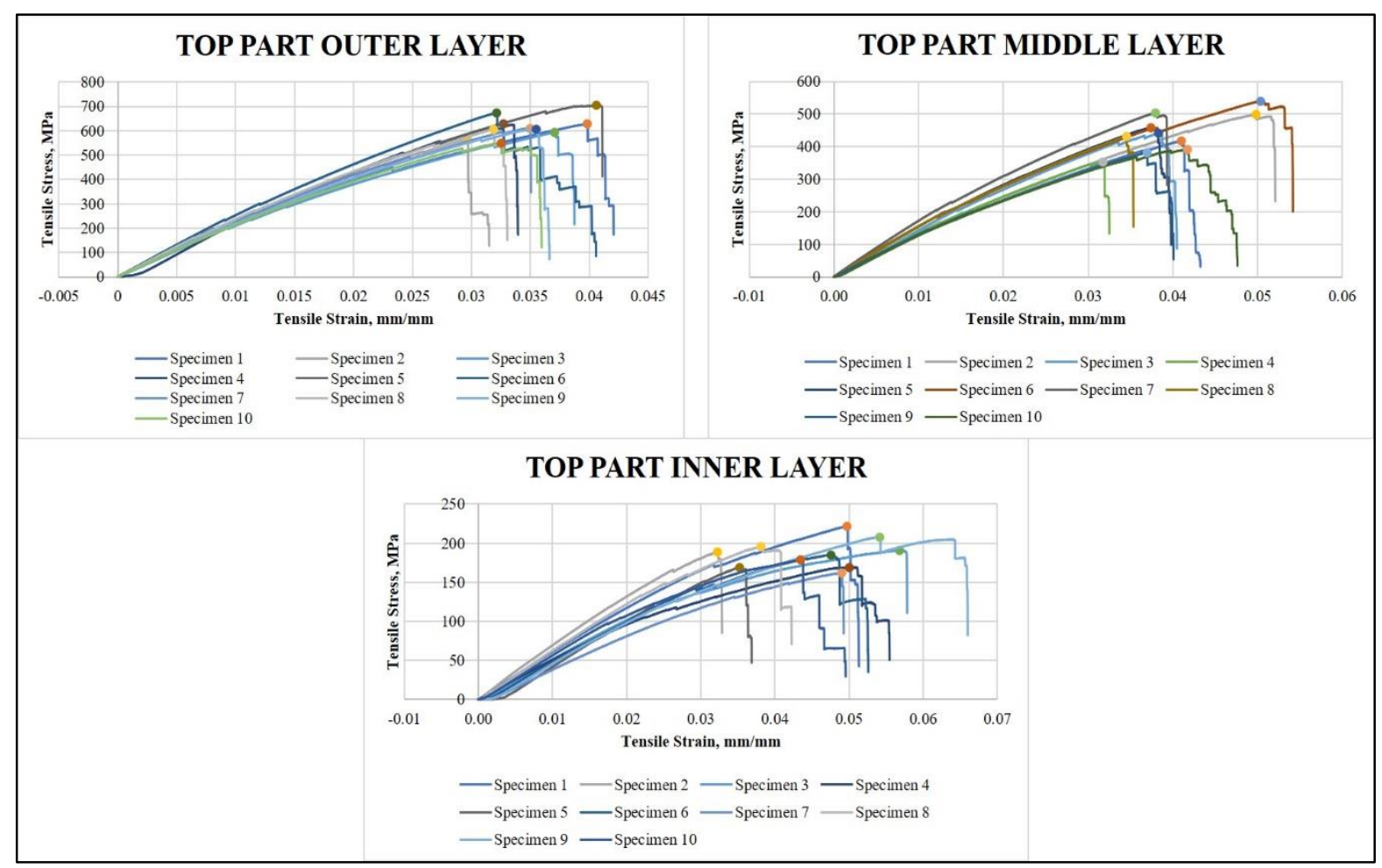

Figure 8. Layered tensile strength of the top part outer layer of the bamboo

Among the three parts of the bamboo considered, the bottom part gave the weakest tensile strength. This trend may be due to the variation of the fibers present in the cross section.

From the specimens tested, usual failure was seen to be within, or at the center of the reduced area gauge length. Some failure occurred at the region where the crosssection tapers from the grip to the neck of the dogbone. Other specimens failed first at tip $\mathrm{f}$ the reduced area gauge length and continue to break at other location from both ends until total failure was achieved. 


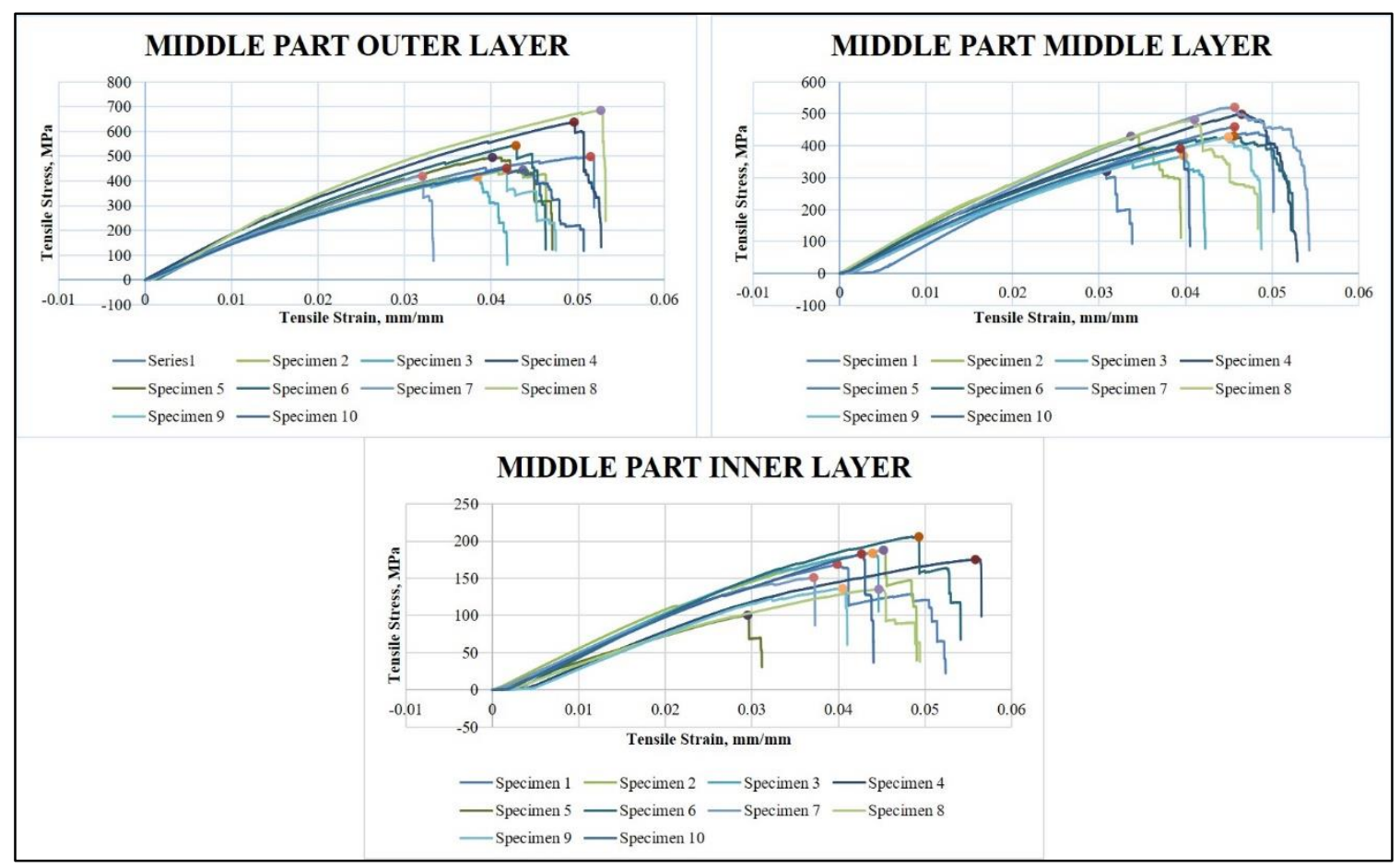

Figure 9. Layered tensile strength of the middle part of the bamboo

\section{Compressive Strength Tests}

The specimen for the compressive test were prepared according to ASTM D143. The test was done with a compressive loading rate of $0.6 \mathrm{~mm} / \mathrm{min}$. Specimen were obtained from different parts of the bamboo culm: top, middle, and bottom parts. The size of the specimens depended on the thickness of the bamboo being tested. There are different specimen sizes for each portion of the bamboo culm. There were 10,11, 12 specimens tested for top, middle, and bottom part, respectively.

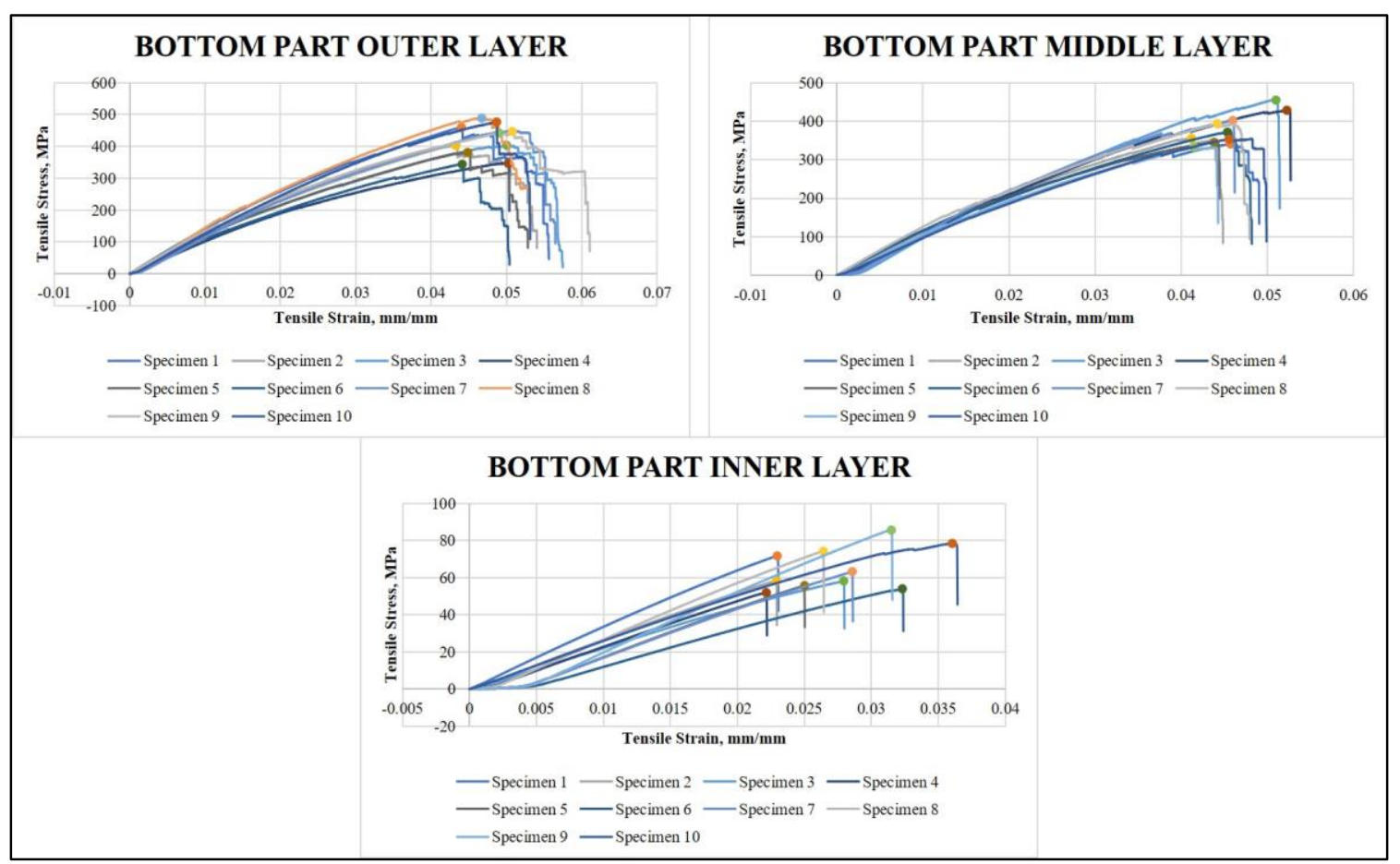

Figure 10. Layered tensile strength of the bottom part of the bamboo 


\section{Top Part}

The top part of the bamboo culm recorded the highest compressive strength with an average value of $76.84 \mathrm{MPa}$. Usual failure was more evident at the outer portion of the specimen, which is the green part or the skin of the bamboo.

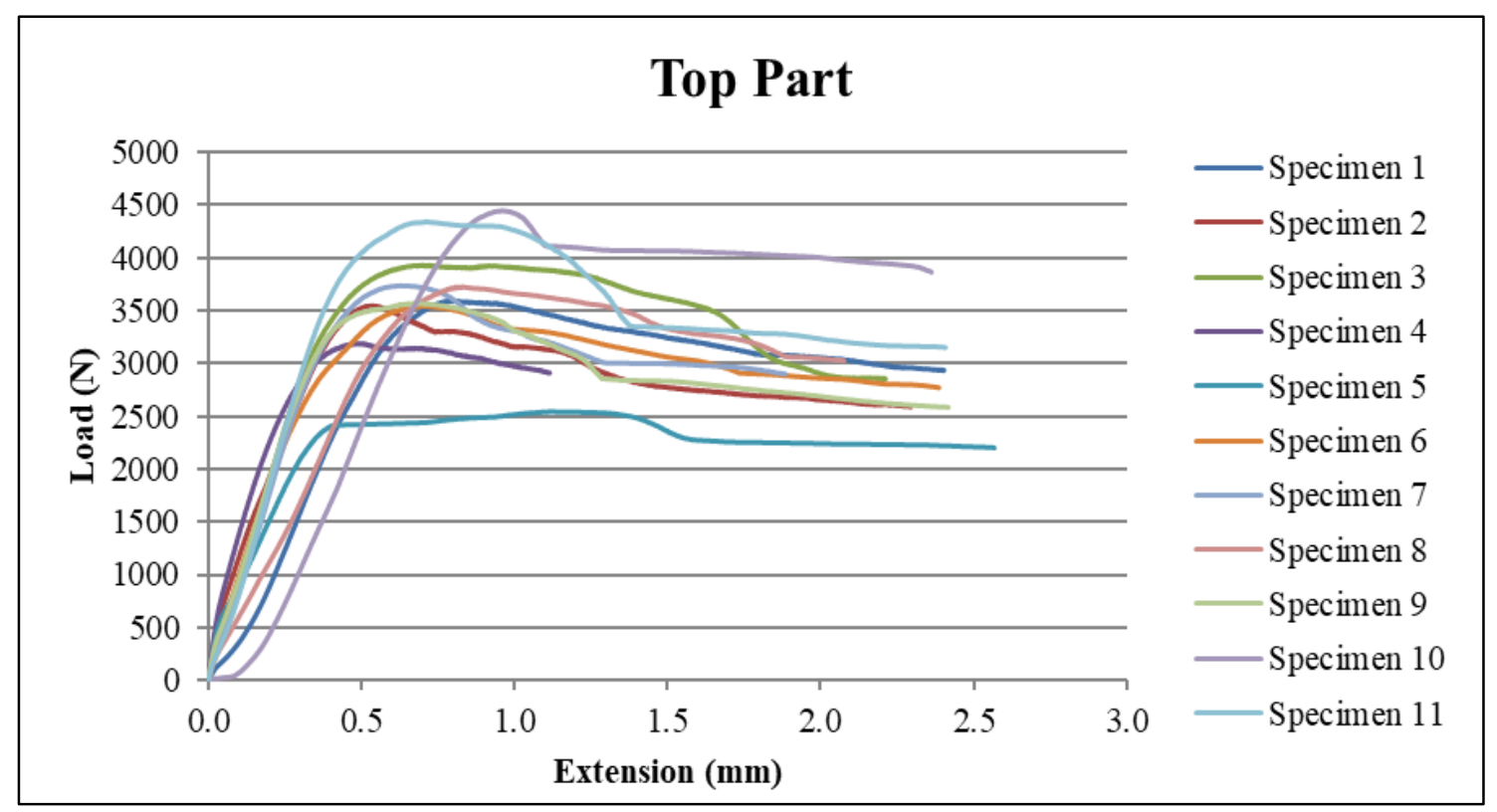

Figure 11. Load vs extension graph for the compressive stress of the top part of the bamboo

\section{Middle Part}

The middle part of the bamboo culm recorded the lowest compressive strength with an average value of $62.55 \mathrm{MPa}$. Usual failure can be seen in the green part of the bamboo culm. The behavior of the specimen during testing is shown in Figure 12.

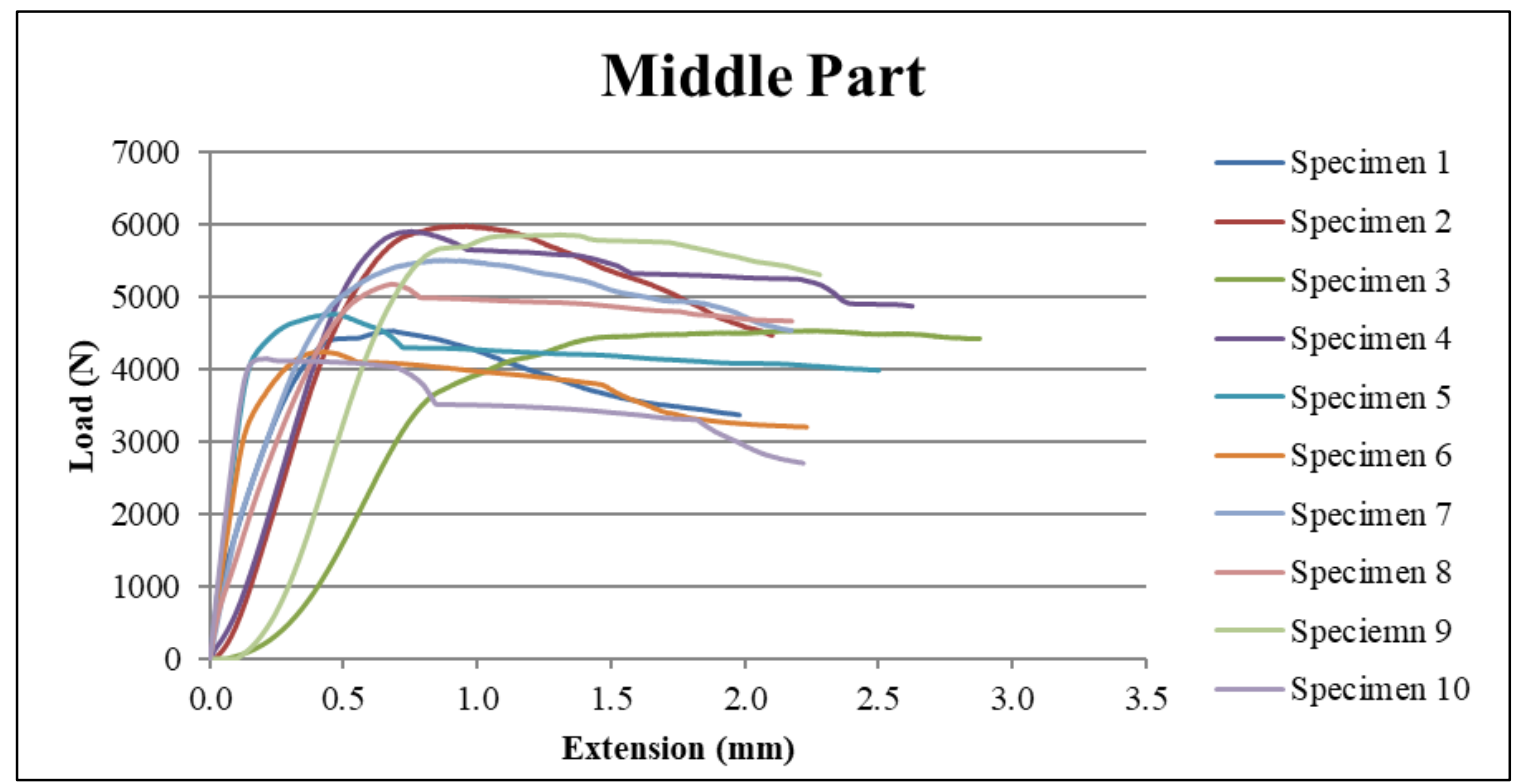

Figure 12. Load vs extension graph for the compressive stress of the middle part of the bamboo 


\section{Bottom Part}

The bottom part of the bamboo culm recorded compressive strength with an average value of $69.49 \mathrm{MPa}$. Failure can be seen in the outer portion of the bamboo. The skin of the bamboo dispersed from the body of the culm.

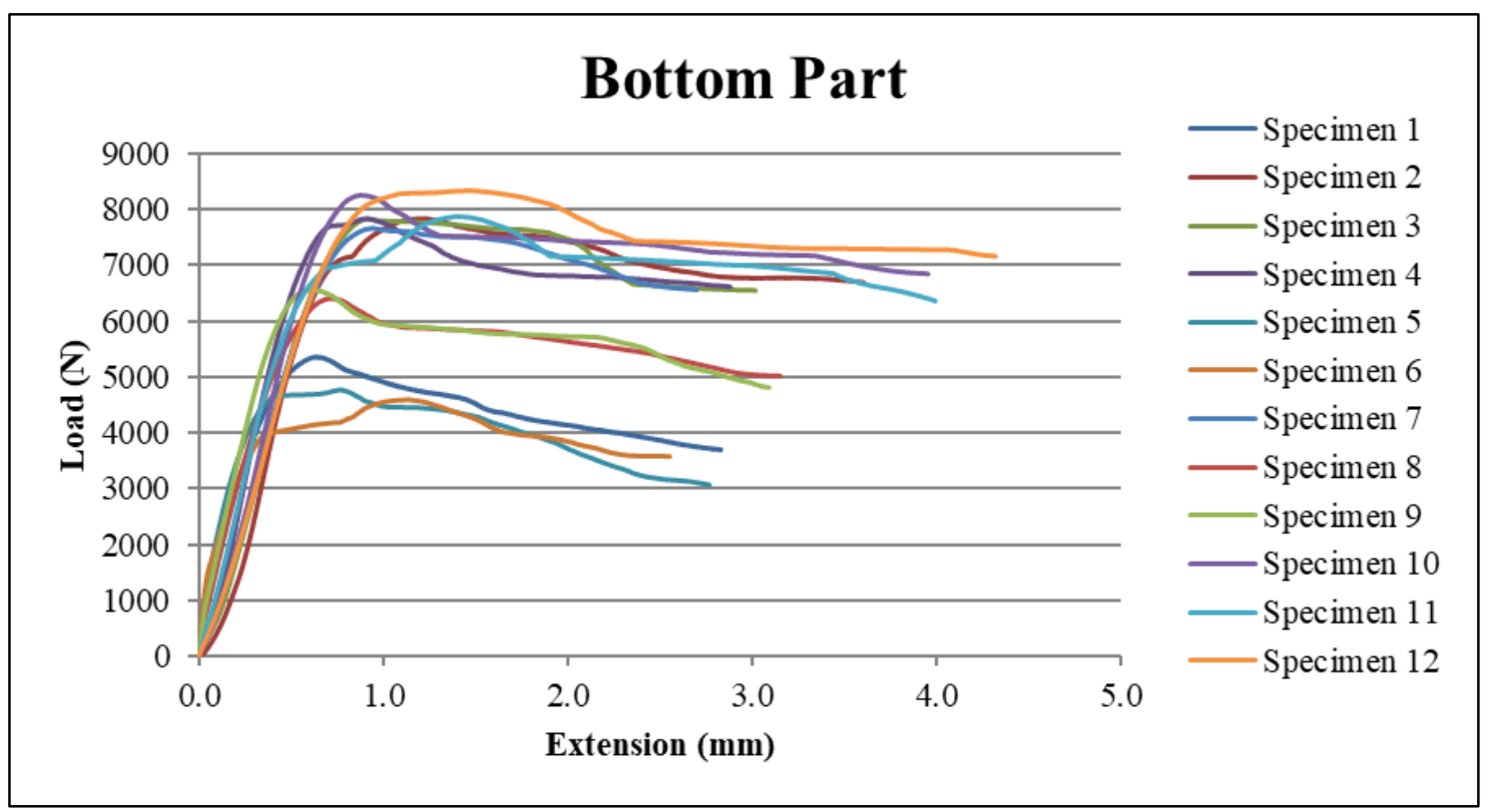

Figure 13. Load vs extension graph for the compressive stress of the bottom part of the bamboo

\section{ANSYS Model}

Before doing the simulation in ANSYS, the geometric properties of the beam must be defined first. For the analysis, a rectangular cross-section was used as shown in Figure 14. The beam's height is $10.76 \mathrm{~mm}$ and its base length is $10 \mathrm{~mm}$. The neutral axis was located at $4.03 \mathrm{~mm}$ from the bottom of the cross-section and the calculated moment of inertia is $1668.36 \mathrm{~mm}^{4}$. The length of the beam is equal to $150 \mathrm{~mm}$. The element type used for meshing was also automatically set by the program to SOLID187. This type of element is a higher order 3D element with 10 nodes. It also has a quadratic displacement behavior and is well suited to modeling irregular meshes. This kind of element can have large displacements and strains. Moreover, it has mixed formulation capability for simulating deformations of nearly incompressible elastoplastic materials. [9]

There were two simulation models for the beam analysis, one was for orthotropic behavior and the other was for the isotropic behavior. Two factors were investigated in the ANSYS model: deflections and normal stresses. Each model was divided into 4 layers: three layers were under tensile behavior and the top layer was under compression. To determine which layer/s would be under tension or compression, mechanical analysis was conducted to find the location of the neutral axis. From the experiment done in tensile strength, it was found out that the outer layer has the highest tensile strength. From this result, the configuration of the beam for the flexure test is such that the outer layer is positioned at the bottom and the inner layer is positioned at the top. Figure 14 shows the configuration of the geometry in ANSYS.

The material properties that were obtained from the experimental tests were checked using Hooke's Law before they were inputted into the ANSYS models. Table 1 
shows the material properties that were incorporated into the equation of Hooke's Law and Table 2 shows the results of the calculation of the uniaxial tensile stress for each layer using Hooke's Law for orthotropic material. The stresses from the experiment was determined by getting the average stresses from each layer of the different parts of the culm. These stresses were recorded in the computer connected to the UTM. Each recorded maximum load from the experiment was used for the ANSYS model as the applied load to get the stress and deflection.

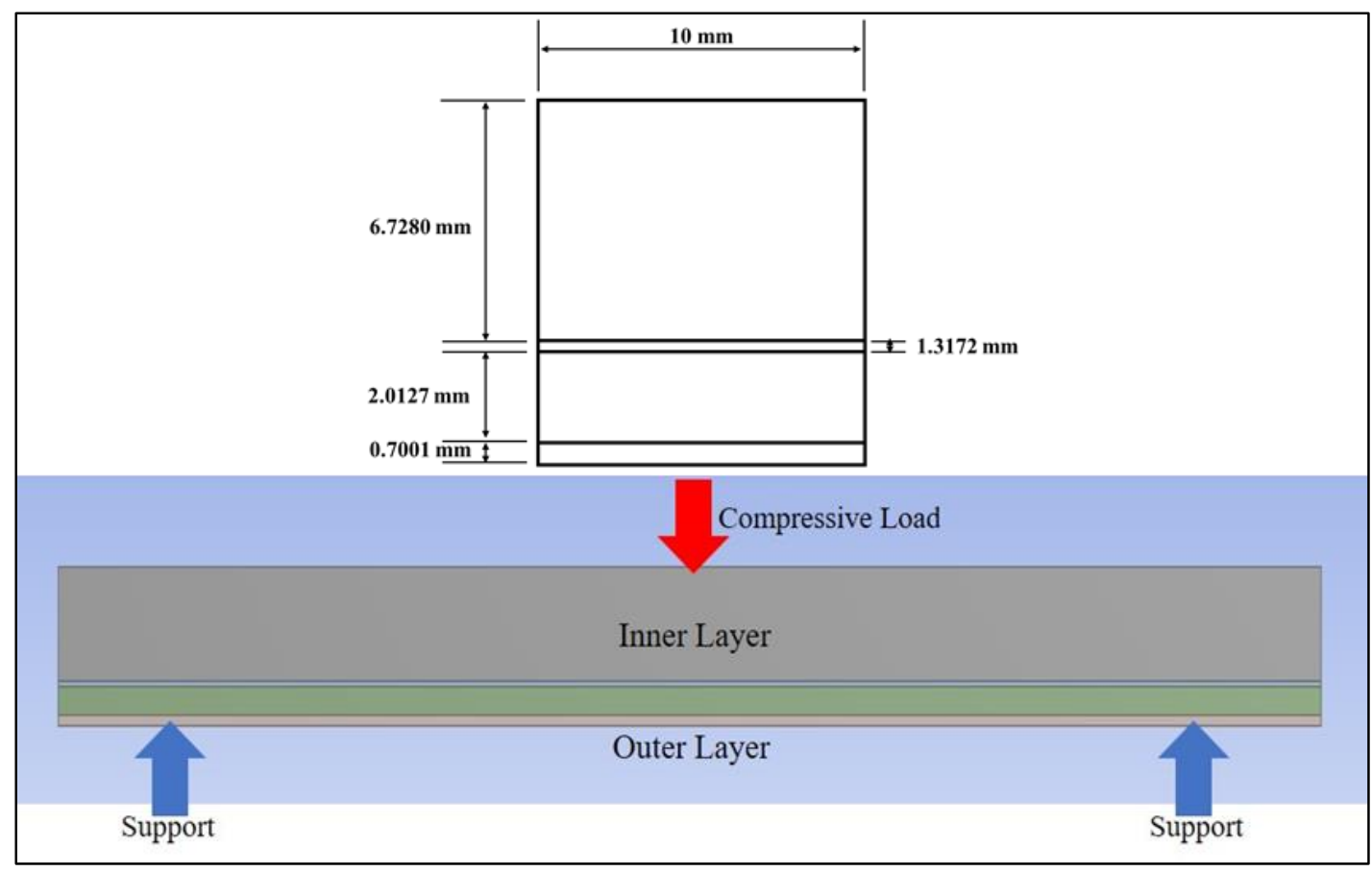

Figure 14. Geometry of the beam for ANSYS modelling

Table 2. Results from Hooke's Law to Check the Orthotropic Properties

\begin{tabular}{|l|c|c|c|c|}
\hline LAYERS & $\begin{array}{c}\text { Strain } \\
(\%)\end{array}$ & $\begin{array}{c}\text { Stress (MPa) } \\
\text { (from HL) }\end{array}$ & $\begin{array}{c}\text { Stress (MPa) } \\
\text { (from expt) }\end{array}$ & Error (\%) \\
\hline Inner & 3.87 & 139.33 & 138.22 & 0.79991 \\
\hline Middle & 4.23 & 420.58 & 417.24 & 0.80002 \\
\hline Outer & 4.18 & 517.22 & 513.12 & 0.79996 \\
\hline
\end{tabular}

The results from the ANSYS models is discussed in the next section along with the results from the flexural strength test. Figures 15 and 16 show the typical results for deflection and normal stress from the ANSYS analysis, respectively.

The average deflection obtained from the orthotropic ANSYS model is 10.92 $\mathrm{mm}$ while from the isotropic model is $9.02 \mathrm{~mm}$. The average deflection obtained from the experiment is $11.21 \mathrm{~mm}$.

The average compressive stress obtained from the orthotropic ANSYS model is 43.02 MPa while from the isotropic ANSYS model is $48.82 \mathrm{MPa}$. For the tensile stress, the average value obtained is $138.80 \mathrm{MPa}$ from the orthotropic model and is $143.12 \mathrm{MPa}$ from the isotropic model. The average compressive stress from the mechanical calculation is $50.36 \mathrm{MPa}$ and the average tensile stress is $145.78 \mathrm{MPa}$. 


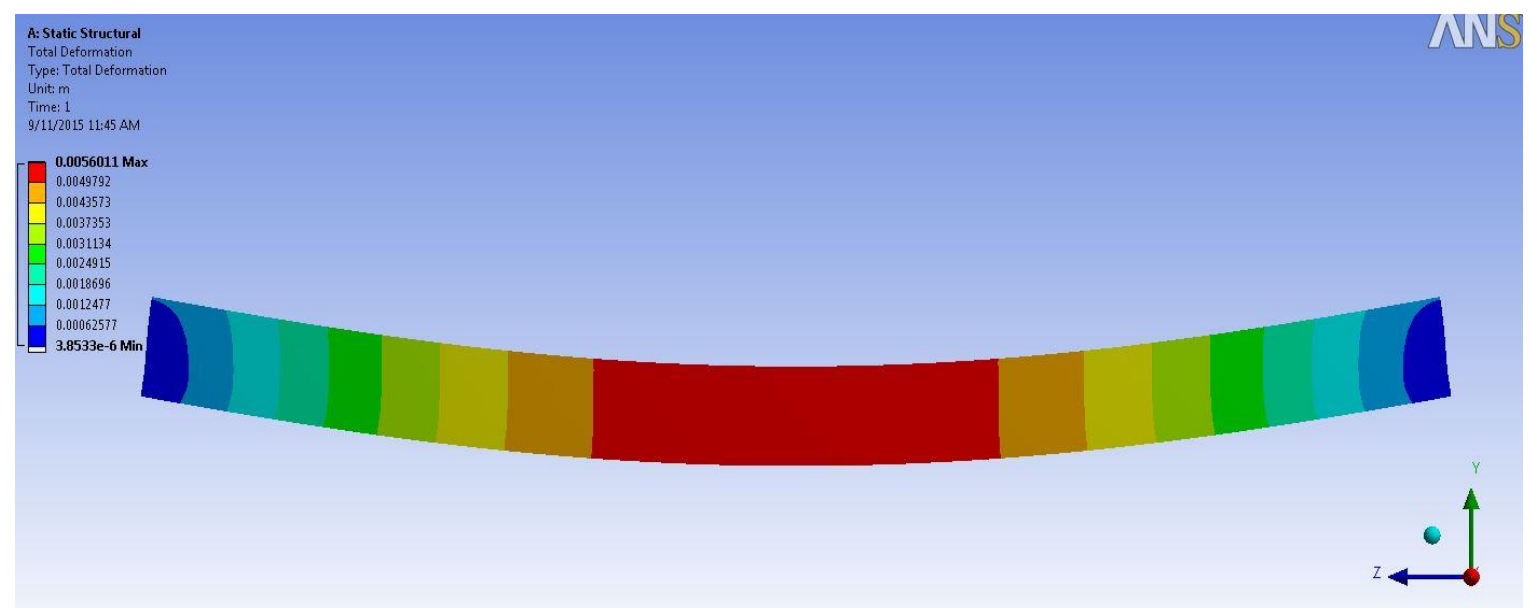

Figure 15. Deflection of one sample from ANSYS

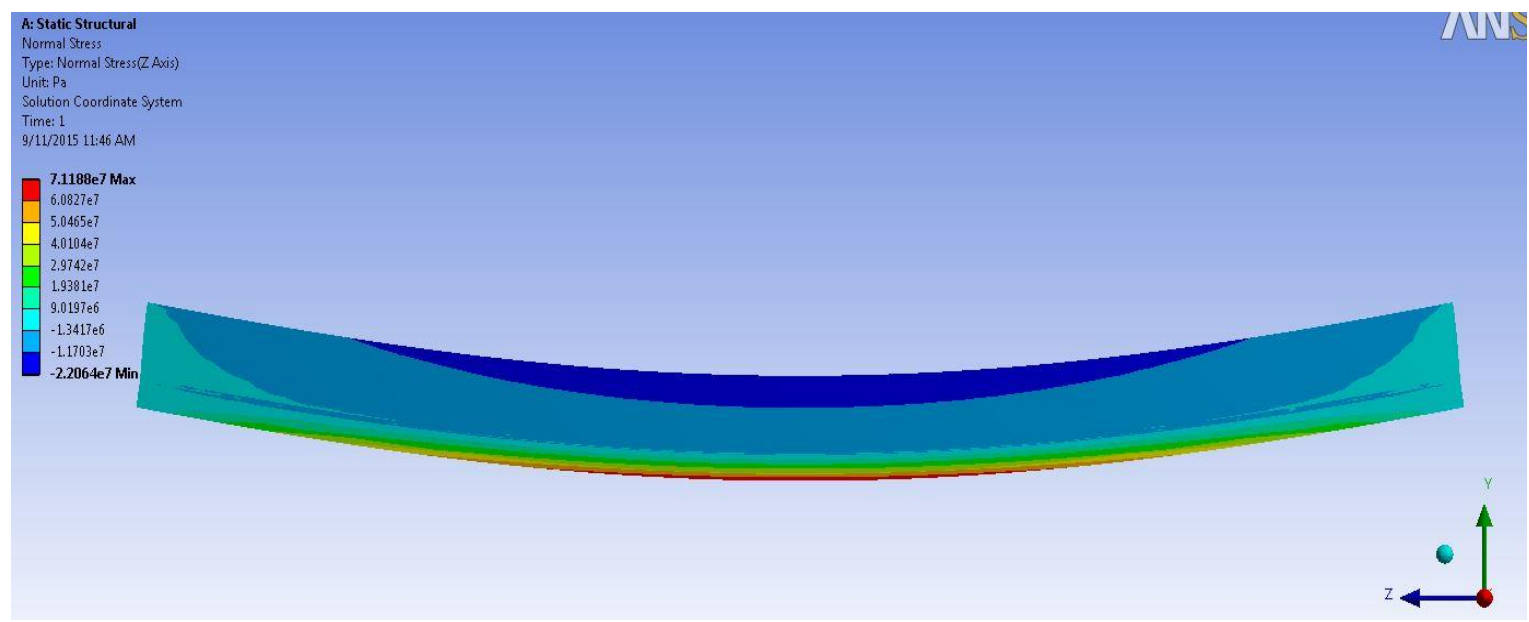

Figure 16. Typical normal stress distribution corresponding to an applied load of one sample from ANSYS

\section{Flexure Strength Test}

Twelve specimens were subjected to flexure test to validate the simulation model done in ANSYS. The deflection and normal stress were compared to the results obtained from the model. Table 3 summarizes the deflection obtained from the flexure laboratory test. A span of equal to $160 \mathrm{~mm}$, on the average, and a loading rate of $0.6 \mathrm{~mm} / \mathrm{min}$ was used for the three-point flexure test. The maximum compressive loads that were recorded from the experiment were used in the ANSYS model to compare the deflections and normal stress.

The average deflection obtained from the experiment is $11.21 \mathrm{~mm}$. The normal stresses were calculated using the concept of transformed section from Mechanics. The average compressive stress is $50.36 \mathrm{MPa}$ while the average tensile stress is $145.78 \mathrm{MPa}$. Table 3 shows the results of flexural strength test done in the laboratory.

The model with orthotropic behavior has lesser error than the model with isotropic model in comparing deflections with the results of the experiment. The orthotropic model has an average error of $3.37 \%$ and the isotropic model has an average error $19.26 \%$. Figure 17 shows the comparison of the results between the experiment and the simulations of FEM from ANSYS in terms of deflection. 
Table 3. Flexure Strength of the Bamboo from Laboratory Test

\begin{tabular}{|c|c|c|c|}
\hline & $\begin{array}{c}\text { Load } \\
(\mathbf{N})\end{array}$ & $\begin{array}{c}\text { Moment } \\
(\mathbf{N}-\mathbf{m m})\end{array}$ & $\begin{array}{c}\text { Deflection } \\
(\mathbf{m m})\end{array}$ \\
\hline 1 & 159.9655 & 5998.7044 & 5.4810 \\
\hline 2 & 218.6061 & 8197.7284 & 7.8956 \\
\hline 3 & 260.8185 & 9780.6930 & 9.0258 \\
\hline 4 & 298.8771 & 11207.8928 & 10.9586 \\
\hline 5 & 306.3480 & 11488.0508 & 11.0837 \\
\hline 6 & 308.2721 & 11560.2034 & 11.0015 \\
\hline 7 & 311.3431 & 11675.3666 & 11.1425 \\
\hline 8 & 332.5804 & 12471.7665 & 12.5252 \\
\hline 9 & 372.1177 & 13954.4153 & 13.4251 \\
\hline 10 & 373.3359 & 14000.0978 & 13.6667 \\
\hline 11 & 380.4056 & 14265.2093 & 13.9965 \\
\hline 12 & 420.0170 & 15750.6364 & 14.2667 \\
\hline
\end{tabular}

The model with isotropic behavior has lesser error than the model with orthotropic model in comparing stresses with the results of the experiment. The orthotropic model has an average error of $14.57 \%$ for the compressive stress and $4.79 \%$ for the tensile stress. The isotropic model has an average error $3.06 \%$ for the compressive stress and $1.82 \%$ for the tensile stress. This is to be expected because the transformed section method used for mechanics computation assumes isotropic material behavior.

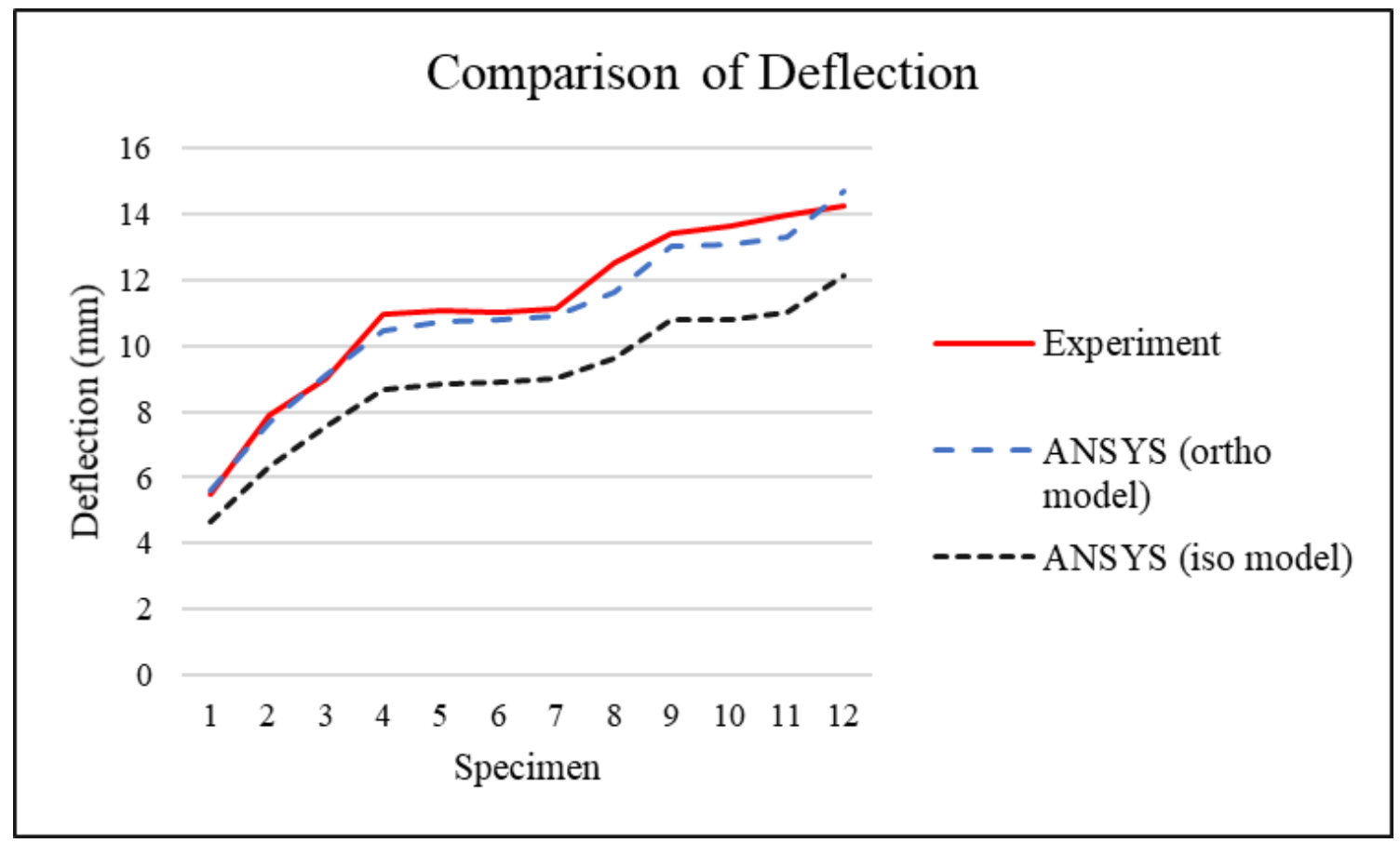

Figure 17. Comparison between ANSYS models and experiment in terms of deflection 


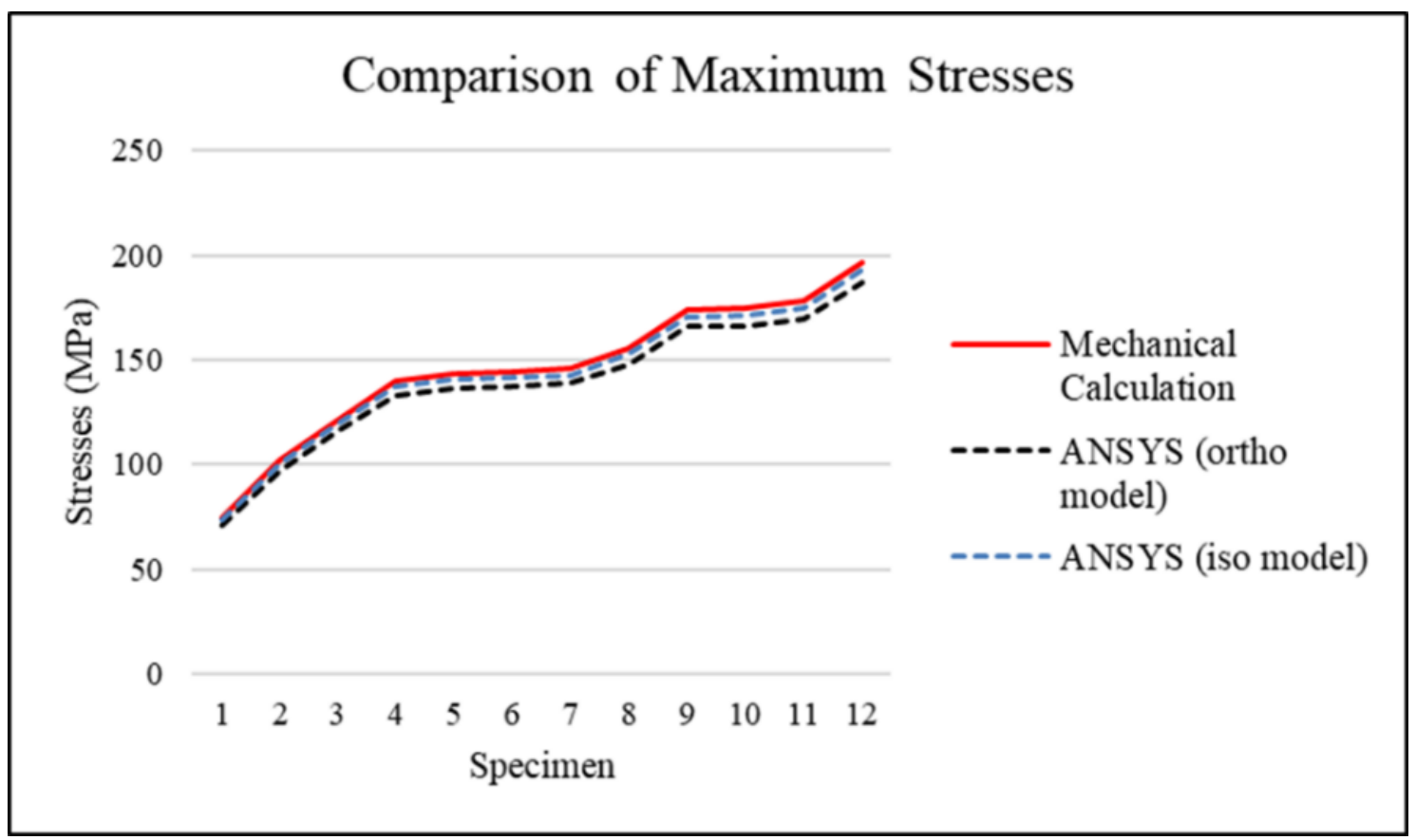

Figure 18. Comparison between ANSYS models and experiment in terms of maximum flexural stress

\section{Conclusions}

It may be observed that tensile strength of bamboo is highly dependent on the behavior of the fibers consisting it. From the experimental results obtained, an increase in tensile strength may be observed from the bottom to top part. Overall, the top part recorded the highest tensile strength per layer, with its outer layers having tensile strength as high as $600 \mathrm{MPa}$. The recorded tensile strength of its middle and inner layers, on the other hand, were approximately $450 \mathrm{MPa}$ and $180 \mathrm{MPa}$, respectively. From this variation in tensile strength across the cross section, it may be concluded that an increase in tensile strength may be observed towards the outer periphery of the bamboo. Experimental results showed that along the thickness (inner, middle, outer layers) and along the culm (top, middle, bottom parts), the tensile stress varies. These results from the layered tensile tests give a more accurate insight on the tensile properties of the bamboo.

Test results also showed that along the culm (top, middle, bottom parts), the compressive stress varies. However, compressive strength of Kauayan tinik did not exhibit any pattern but the values are within the range reported by Janssen in 1981 [10]. The top part of the bamboo culm recorded the highest compressive strength with an average of $76.84 \mathrm{MPa}$. The middle part of the bamboo culm recorded the lowest compressive strength with an average of $62.55 \mathrm{MPa}$. The bottom part of the bamboo culm recorded an average compressive strength of $69.49 \mathrm{MPa}$.

The deflection results from the FEM simulation using the orthotropic material model are in better agreement with the results from the experiment than the results obtained from the isotropic model. The normal stress results from the isotropic model relates closer to the results obtained from the mechanical calculations than the results from the orthotropic model. Therefore, in modeling the material properties of the bamboo to check for deflections, it is better to use the orthotropic model. Based from the FEM 
simulation results, in modeling the material properties of the bamboo to check for deflections, it is more accurate to use the orthotropic model (error of $1.18 \%$ to $7.03 \%$ ).

With these results of investigations, bamboo has proven its potential in the field of engineering. Having strengths as high, or even higher, than that of other materials used in construction, bamboo may obviously be utilized as an alternative. However, further evaluations and investigations shall still be conducted to properly approximate its overall capacity.

The results from this study will aid in setting guidelines in designing with bamboo as the construction material. This research will also contribute more material in understanding different techniques on joining or jointing bamboo materials for construction. Consequently, this study will give more information in finding alternative systems for sustainable and low-cost housing structures.

\section{References}

[1] K.A. Harries, B. Sharma, and M. Richard, "Structural use of full culm bamboo: The path to standardization," International Journal of Architecture, Engineering and Construction, Vol. 1, No. 2, pp. 66-75, 2012.

[2] S. Kaminski, A. Lawrence, and D. Trujillo, "Structural use of bamboo: Part 1: Introduction to bamboo," Structural Engineer, Vol. 94, pp. 40-43, 2016.

[3] A. Awaludin, and V. Andriani, "Bolted bamboo joint reinforced with fiber," Procedia Engineering, Vol. 95, pp. 15-21, 2014.

[4] D.L. Jayanetti, and P.R. Follett, Bamboo in Construction: An Introduction, No. 15, International Network for Bamboo and Rattan, International Development Research Center, Regional Office for South Asia, New Delhi, India, 1998.

[5] University of Alberta, "ANSYS Tutorials - Coupled Structural/Thermal Analysis," 2001 [Online]. Available: http://www.mece.ualberta.ca/tutorials/ansys/ AT/Coupled/Coupled.html [Accessed: June 2015]

[6] L.A. Torres, K. Ghavami, and J.J. Garcia, "A transversely isotropic law for the determination of the circumferential Young's modulus of bamboo with diametric compression tests," Latin American Applied Research, Vol. 37, pp. 255-260, 2007.

[7] Z. Jiang, F. Chen, G. Wang, X. Liu, S.Q. Shi, and H.T. Cheng, "The circumferential mechanical properties of bamboo with uniaxial and biaxial compression tests," Bioresources, Vol. 7, pp. 4806-16, 2012.

[8] Y. Yu, B. Fei, B. Zhang, and X. Yu, "Cell-wall mechanical properties of bamboo investigated by in-situ imaging nanoindentation," Wood and Fiber Science, Vol. 39 No. 4, pp. 527-535, 2007.

[9] "SOLID187" (n.d.) [Online]. Available: https://www.sharcnet.ca/Software/Ansys/17.0/enus/help/ans_elem/Hlp_E_SOLID187.html [Accessed: August, 2016].

[10] J.J.A. Janssen, Bamboo in Building Structures, Thesis (PhD), Eindhoven University of Technology, Eindhoven, Netherlands, 1981. 